University of East London Institutional Repository: http://roar.uel.ac.uk

This paper is made available online in accordance with publisher policies. Please scroll down to view the document itself. Please refer to the repository record for this item and our policy information available from the repository home page for further information.

To see the final version of this paper please visit the publisher's website.

Access to the published version may require a subscription.

Author(s): Dickins, Thomas E. \& Sergeant, Mark J.T.

Article title: Social Dominance and Sexual Orientation

Year of publication: 2008

Citation: Dickins, T.E. \& Sergeant, M.J.T. (2008) 'Social Dominance and Sexual Orientation.' Journal of Evolutionary Psychology, 6 (1) 57-71

Link to published version: http://dx.doi.org/10.1556/JEP.2008.1003

DOI: $10.1556 / J E P .2008 .1003$ 


\title{
Social Dominance and Sexual Orientation
}

\author{
T. E. Dickins ${ }^{1,2 *} \&$ M. J. T. Sergeant ${ }^{3}$
}

Affiliations:

${ }^{1}$ School of Psychology, University of East London, London E15 4LZ, U.K.

${ }^{2}$ Centre for Philosophy of Natural and Social Science, London School of Economics, London WC2A 2AE, U.K.

${ }^{3}$ Division of Psychology, Nottingham Trent University, Nottingham NG1 3JA, U.K.

* corresponding author

\section{Thomas Dickins}

School of Psychology

University of East London

London E15 4LZ

UK

E-mail: $\quad$ t.dickins@uel.ac.uk

Phone: $\quad 0044$ (0)208 2234005

Fax: $\quad 0044(0) 2082234937$ 


\section{Abstract/Summary}

Heterosexual males are reported to display higher levels of physical aggression and lower levels of empathy than homosexual males. A characteristic linked to both aggression and empathy is social dominance orientation (SDO). A significant sex difference has been reported for SDO, with heterosexual males scoring higher than heterosexual females. The precise relationship between dominance and aggression is currently contested. Given the association between SDO, aggression and empathy, and the differences between heterosexual and homosexual males, an analysis of how sexual orientation co-varies with SDO might help to clarify the association between aggression and dominance. SDO scores were derived from heterosexual males $(\mathrm{n}=$ $60)$, heterosexual females $(n=60)$ and homosexual males $(n=60)$. Heterosexual males reported higher levels of SDO than heterosexual females and homosexual males, while heterosexual females scored higher than homosexual males. These differences were analogous for physical aggression. More work is required to thoroughly understand the aetiology of these effects as well as the strategic value of the behaviours, but for now we have reason to further investigate the organizational hormone hypothesis put forward in this paper.

Keywords: Social Dominance Orientation, Direct Aggression, Indirect Aggression, Empathy, Sexual Orientation 


\section{Introduction:}

Aggression is a strategic behaviour with known sex differences such that young males initiate more aggression and are more physically aggressive (Daly \& Wilson, 1988; Harris, 1996; Mesquida \& Weiner, 1996). One possible strategic outcome is increased personal dominance or a rise in social rank (Archer, 2006), which will have positive fitness consequences not least in terms of reproductive opportunities. Another possible strategic outcome is increased group level dominance as males band together in coalitions for mutual fitness enhancing benefit (see below). It is this latter strategic possibility that we sought to explore in this paper.

Recently, Van Vugt, De Cremer and Janssen (2007), have shown that men will behave more cooperatively in economic games when they perceive an out-group threat. Women were impervious to such manipulations and their cooperation remained constant across all conditions. Van Vugt et al. were inspired by a large social psychological literature showing women to be more interpersonally oriented and men more group-oriented, thus indicating a dispositional sex difference.

Sidanius and colleagues (Pratto \& Hegarty, 2000; Sidanius, Pratto, \& Bobo, 1994; Sidanius, Levin, Liu \& Pratto, 2000; Sidanius, Pratto, van Laar, \& Levin, 2004) have developed the notion of Social Dominance Orientation (henceforth SDO), which captures people's degree of approval of dominance and of egalitarian relationships between their own group and out-groups. High SDO people are in favour of inequalities between groups and tend to hold opinions about some groups being more worthy than others. On the other hand, low SDO people are in favour of equality 
between groups. In general, high SDO people have a "view of human existence as zero-sum and (as a) relentless competition between groups" (Sidanius et al., 1994: 999). SDO is to be understood as "a very general orientation... (that) is considered to be a normally distributed individual difference variable, having its aetiology in both cultural ... and biologically influenced factors.” (Ibid: 999).

Sidanius et al. (2000) make some specific hypotheses about sex differences and SDO (see also Pratto \& Hegarty, 2000), which are commensurate with Van Vugt et al. A key prediction of Parental Investment Theory (Trivers 1972) is that due to higher costs of reproduction for females, they will be choosier about partners, seeking resources and status in their mates, whilst males will be doing what they can to be chosen; including attempting to increase status and monopolize resources. This leads to intra-sexual competition, which in turn can lead to strategic coalitions between males in order to improve their individual lot (though note that personal dominance is not related to SDO, according to Pratto et al. 1994, so they should be regarded as separate variables). Females, on the other hand, are rarely without mating opportunities and are therefore less likely to require coalitional help of this kind (Tooby and Cosmides, 1988). Given this, males, on average, were predicted and found to score higher on SDO than females (Pratto et al., 1994). It is also worth noting that Sidanius et al. (1994) reported that SDO is negatively correlated with empathy. According to some researchers (e.g. Baron-Cohen, 2002) females, on average, score higher on empathy scales (see below).

SDO appears to be a candidate psychological disposition, accounting for the findings of Van Vugt and others, at the proximate level. Axelrod and Hammond (2003) ran 
an agent based simulation to investigate the possible selection of what they termed ethnocentric strategies. They argued that ethnocentrism is a 'syndrome of attitudes' that includes a great deal of in-group favouritism, not dissimilar to that demonstrated by Sidanius, Van Vugt and others. In Axelrod and Hammond's model agents were asexual immigrants who could recognise other individuals as members of their group, and who were inclined to cooperate with individuals of a particular group or not. In other words, some individuals would always cooperate with their own group and not others, others would cooperate with no one, and so forth. Under a large variety of parameters ethnocentrism always came to dominate as a strategy, and was evolutionarily stable. Groups of individuals who only cooperated with their own members all individually ramped up fitness benefits, reproducing more and coming to establish larger territories in the environment they inhabited. Meanwhile, egotistic agents who helped no one were always at a disadvantage relative to neighbouring groups of ethnocentrics. Crucially, when the cost of helping increased and the ability to discriminate group membership was lost (through mutation) cooperation collapsed. It seems that aggressive ethnocentrism contributes to the emergence of cooperation.

Axelrod and Hammond's (2003) simulation establishes that ethnocentric, coalitional action can have huge benefits for the individuals concerned in a simple, asexual world. Of interest is how such dynamics relate to the emergence of coalitional aggression in real, sexual populations. Wrangham (1999) discusses the evolution of coalitional killing, directly relating this to warfare. The thesis he favours is the Chimpanzee Violence Hypothesis. The claim is that selection has bequeathed adult male chimpanzees the ability to weigh the relative costs and benefits of violent attacks on rival groups and this was an ability that our common ancestors also had. 
Wrangham suggests that one proximate cause of coalitional violence is imbalance in power, the key aspect being the low-cost nature of lethal raids for the aggressors. When three male chimps cooperate to attack one from another group, two can easily disable the lone chimpanzee whilst the other finishes him off. The ultimate benefit is that this reduces the number of males in neighbouring groups affecting their sex ratio, in favour of unmated females, who are a desirable resource. Such imbalances are a consequence of the fission-fusion pattern that chimpanzees operate. Individuals can be on their own part of the time, or in groups of varying sizes. Party size is in large part influenced by the availability of fruit: the more fruit there is in a region the larger a party can be. If a neighbouring group has smaller parties, on average, the costs of raiding are markedly lowered for the former group. In short, it seems lethal-raiding of this sort has emerged as a consequence of scramble competition for resources.

Tooby and Cosmides (1988), over a decade before Wrangham, noted that the incidence of scramble competition in various populations would lead one to expect many examples of coalitional aggression and killing. However, they claim that only chimps, dolphins and humans aggress in this way. Tooby and Cosmides reasoned that this was because these species have highly sophisticated social cognition. This cognition is directed toward the resolution of complex social problems - detecting and excluding free-riders, and generally maintaining a number of complex interactions within a group, and in particular maintaining long lasting dyadic interactions within a group. The dispositions underpinning SDO, which may also capture the findings of Van Vugt and others, can be understood as an aspect of this sophisticated cognition within human populations. It is possible to imagine a scenario, not unlike that of Axelrod and Hammond's, that would lead to ethnocentrically cooperating groups. If 
the ecology could support large group sizes at certain times and certain places then new selection pressures to resolve free-riding issues and generally support cooperation would emerge, and within such populations sexual males would benefit from border raids and other aggressive coalitional acts in order to acquire access to key resources.

In order to build a complete explanation of male aggression the proximate mechanisms of its development must also be considered. It is possible that the malebias in physical aggression is a consequence of mechanisms organized by exposure to prenatal testosterone, for males are typically exposed to greater levels of testosterone in the amniotic sac. Supporting evidence for this possibility comes from work using second-to-fourth digit ratio as a proxy for prenatal testosterone exposure (see Manning, 2002). For example, Bailey and Hurd (2005) found that males with lower, i.e. more masculine, second-to-fourth digit ratios had higher physical aggression scores than other groups. Millet and Dewitte (2006) reported that male-typical second-to-fourth digit ratio was predictive of cooperative behaviour. This was contrary to their predictions, but clearly makes sense in light of the relationship between coalitional aggression and cooperation outline above. Interestingly, Neave, Laing, Fink and Manning (2003) have found, also using second-to-fourth digit ratio as a proxy, that prenatal testosterone exposure is positively related to perceived dominance, such that males with low, male-typical ratios are seen as more dominant than other males. Circulating testosterone levels had no relationship to perceived dominance. They hypothesize that prenatal testosterone organizes facial features to signal dominance. 
There is evidence from other sources too. Cohen-Bendahan, Buitelaar, van Goozen, Orlebeke and Cohen-Kettenis (2005), using a twin-study paradigm, found that 'opposite-sex twin girls showed a more masculine pattern of aggression than same sex girls' (p. 230), these girls having had a higher exposure to prenatal testosterone. Finally, Berenbaum (1999) and colleagues (Berenbaum \& Resnick, 1997; Berenbaum, Duck \& Bryk, 2000) have extensively reported on male-typical behavioural profiles of females with congenital adrenal hyperplasia $(\mathrm{CAH})$. $\mathrm{CAH}$ females have atypically high exposure to prenatal testosterone. Berenbaum and Resnick (1997) in particular have demonstrated that adolescent and adult females with CAH are more physically aggressive than control females.

In light of the above evidence it is perhaps not surprising that prenatal androgen exposure has also been linked to homosexuality with the suggestion that atypically low exposure leads to more female-oriented brain organization. Some evidence comes from digit ratio work. For example, Lippa (2003) reports that homosexual males had significantly higher second-to-fourth digits ratios than heterosexual men, i.e. a less male-typical profile. However, McFadden, Loehlin, Breedlove, Lippa, Manning and Rahman (2005) conducted a reanalysis on five keys studies on digit ratio and sexual orientation. They concluded that there are ethnic differences in this effect, and it is most prominent only in those who identify as White or Caucasian. This does not rule out a prenatal testosterone effect but suggests caution interpreting digit ratio results. Indeed, in an authoritative survey of the neuro-developmental, cognitive and animal literature, Rahman and Wilson (2003) concluded that prenatal testosterone exposure was most likely causally involved in the development of homosexuality. More specifically, they think that testosterone exposure affects 
amygdala development, which is known to be sexually dimorphic and involved in many of the behaviours of concern to this paper, not least aggressive response and empathy.

Sergeant, Dickins, Davies and Griffiths (2006) reported on differences in aggression and empathy between male heterosexual and homosexual participants. Previous work (e.g. Blanchard, McConkey, Roper \& Steiner, 1983) had shown homosexual males to be less physically aggressive than heterosexual males, but no findings had been presented on indirect aggression. Indirect aggression has been associated with heterosexual females, with some claiming that female levels of aggression are the same as males but that it is more often expressed indirectly (Campbell, 1995). Indirect aggression includes manipulative behaviours that are aimed at causing harm and, as with direct aggression, is comprised of a number of measurable components (Forrest, Eatough \& Shevlin, 2005).

Using self-report measures, Sergeant et al. (2006) found that homosexual males displayed significantly lower levels of physical aggression than heterosexual males, but the levels of indirect aggression were comparable. Furthermore, homosexual males had significantly higher levels of empathy than heterosexual males, in line with heterosexual female performance. During the discussion, Sergeant et al. cautiously hypothesized that reduced prenatal testosterone exposure might well affect amygdala functioning in homosexual males leading to a female-shift in empathic behaviour, in line with Rahman and Wilson (2003). 
As we have seen, there is evidence to suggest that prenatal testosterone exposure affects direct aggression. We have suggested that such aggression has strategic value either for personal or group level dominance in males. To this end it might be that what motivates direct aggression are dispositions to seek dominance, where aggression is understood as a useful tool (Mazur and Booth, 1998). In this case, prenatal testosterone will act to organize proximate dominance seeking mechanisms as well as lower thresholds to direct aggression compared with females. We have reason to believe this given the reported sex differences in SDO. In order to begin exploring this idea we hypothesized that heterosexual males would differ from homosexual males on physical aggression and empathy as Sergeant et al. (2006) demonstrated. Furthermore, we predicted that heterosexual males would be significantly higher in SDO than heterosexual females and homosexual males.

\section{Method}

\subsection{Participants}

A total of 60 heterosexual females (mean age $=23.83$ years, $S D=4.79$ years), 60 heterosexual males (mean age $=23.55$ years, $\mathrm{SD}=5.04$ years) and 60 homosexual males (mean age $=21.97$ years, $\mathrm{SD}=5.53$ years) participated

Sexual orientation was established using a series of four separate Kinsey Scales (Kinsey, Pomeroy \& Martin, 1948) designed to assess sexual identity, attraction, behaviour and fantasies. Each scale has a seven-point rating, running from 0 (completely heterosexual interest/response) to 6 (completely homosexual 
interest/response). Mean orientation scores from the four scales were $0.09(\mathrm{SD}=0.21)$ for the heterosexual males, $0.19(\mathrm{SD}=0.23)$ for the heterosexual females and, 5.85 $(\mathrm{SD}=0.26)$ for the homosexual males. Clear differences were thus demonstrated in self-reported sexual orientation between the heterosexual and homosexual groups. This is consistent with Sergeant et al. (2006).

All of the heterosexual participants were recruited online. The homosexual participants were drawn from student Lesbian, Gay, Bisexual and Transgender (LGBT) organizations in the U.K. A standardized e-mail was sent to the president of each organisation explaining the goals of the current research and requesting that a link to this study be distributed to their members. Heterosexual males were recruited via a link posted on two student orientated online research websites, the 'Social Psychology Network' and 'Psychological Research on the Net' over a 2-month period (apply to author for details).

The use of an online sample reduces the problems of recruiting participants. However, it is possible that an online sample may not be representative of the wider population. Sergeant et al. (2006) directly addressed this problem and found good generality when compared to more traditional methods. Furthermore, social desirability effects are reported to be much reduced in online sampling (Joinson, 1999). There is, of course, a lack of direct control over participants. In order to increase researcher control, participants were provided with clear and explicit instructions to follow, IP addresses were recorded to prevent multiple submissions and the online survey-authoring tool was deliberately selected for its presentational consistency across web browsers. 


\subsection{Materials}

The aggression, indirect aggression, and empathy measures used in this study were the same as those adopted by Sergeant et al. (2006). The Social Dominance Orientation Scale (Pratto et al., 1994) was also adopted.

\subsubsection{The aggression questionnaire (AQ)}

This 29-item scale was developed by Buss and Perry (1992) specifically to divide direct aggression into a series of factor-analytically derived sub-traits: physical and verbal aggression (motor components); anger (affective component) and hostility (cognitive component). All sub-traits demonstrate a high level of internal consistency (Cronbach's alphas ranging from 0.72 to 0.85 ). Given the specificity of previously reported differences in aggression between heterosexual and homosexual males (Gladue \& Bailey, 1995), the AQ may detect differences that would otherwise have been missed by more global measures of aggression.

\subsubsection{The indirect aggression scale - aggressor version (IAS-A)}

The IAS-A (Forrest et al., 2005) is a 25-item psychometric tool specifically designed for the self-assessment of indirect aggression among adults. Based on exploratory factor analysis, indirect aggression is divided into three sub-traits: social exclusion (actively excluding someone from social situations/interactions); use of malicious humour (using humour to harm an individual); and, guilt induction (the intentional induction of guilt), which show a high level of internal consistency (Cronbach's alphas ranging from 0.81 to 0.89 ). Participants are asked to evaluate how often they 
used an indirectly aggressive strategy towards someone over the last 12 months, with their responses being evaluated on a 5 point Likert scale $(1=$ never, to $5=$ regularly $)$.

\subsubsection{The empathizing quotient (EQ)}

This 60 -item scale was developed to assess empathy, defined as the ability to identify mental states and respond with an appropriate emotional reaction (Baron-Cohen, Richler, Bisarya, Gurunathan \& Wheelwright, 2003). While many previous empathy measures have been developed, they have frequently tapped into emotional arousability, self-confidence, sensitivity or non-conformity rather than empathy per se (Lawrence, Shaw, Baker, Baron-Cohen \& David, 2004). The EQ is both a reliable and valid measure of empathy (Lawrence et al., 2004). It is compose of 60 items, 40 of which are designed to assess empathy and 20 acting as filler items. Participants are asked to say how much they agree or disagree with empathy related statements (i.e., 'I really enjoy caring for other people') using a four-point Likert scale (ranging from 'strongly disagree' to 'strongly agree'). The EQ has demonstrated a high level of internal consistency (Cronbach's alphas of 0.92; Baron-Cohen \& Wheelwright, 2004).

\subsubsection{Social Dominance Orientation (SDO)}

This 14 item scale was developed by Pratto, Sidanius, Stallworth and Malle (1994) to measure an individual's degree of preference for inequality among social groups. Participants are asked to evaluate how positive or negative they feel about each of 14 statements. Statements include items such as 'Some groups of people are simply not the equal of others'. Participants are required to use a 7 point Likert scale $(1=$ very negative, to $7=$ very positive). This is a reliable and valid measure, with Pratto et al. (2004) reporting reliability coefficients of 0.90. Pratto et al. (1994) have demonstrated 
that SDO is higher in males, that high-SDO individuals seek hierarchy enhancing jobs, that SDO is different from personal dominance, authoritarianism and conservatism, and that SDO is negatively correlated with empathy, tolerance, communality, and altruism.

\subsection{Procedure}

All of the above measures and demographic scales were coded onto an online presentational format using the autoform system of Nottingham Trent University (apply to second author for details). This is an online survey-authoring tool optimized for fast downloading, widespread browser compatibility and clarity of display. A link to the finished survey was then distributed to the participants (see above).

Before taking part in the study, participants were required to read an introductory text that informed them of the aim of the study and of all pertinent ethical issues. All participants were required to provide explicit consent that they had read and understood both the nature of this study and were more than 18 years old. All procedures were approved by the Psychology Ethics Committee of Nottingham Trent University.

\section{Results:}

Mean scores from all orientation groups are displayed in Table I.

[INSERT TABLE I HERE] 


\subsection{Multivariate Analysis}

A between-subjects MANOVA was applied to the data with Sexual orientation group (Heterosexual males, Heterosexual females, Homosexual males) as the betweensubjects variable, and scores for each measure as the dependent factors ${ }^{1}$. There was a significant multivariate difference based on Sexual Orientation $\left(\mathrm{F}_{(16,338)}=5.20, p=\right.$ 0.01; Wilks' $\lambda=0.61 ; \eta_{\mathrm{p}}^{2}=0.22$ ). Based on the guidelines developed by Cohen (1988), the effect size measure suggests the difference between sexual orientation groups is at best moderate in magnitude $\left(\eta_{\mathrm{p}}{ }^{2}=0.22\right)$. Results of univariate analysis for each dependent variable are shown below in Table II.

\section{[INSERT TABLE II HERE]}

Given the significant findings for the univariate analyses of Sexual orientation group for SDO, physical aggression, anger, guilt induction, empathy, posthoc comparisons were run on these data. Bonferroni methods were selected as the basis for these comparisons in order to control the Type I error rate while maximizing the statistical power of the test (Field, 2003). The results of these posthoc comparisons are shown below in Table III:

\section{[INSERT TABLE III HERE]}

A significant difference was found between each of the three groups for SDO, such that heterosexual males reported higher levels of SDO than both heterosexual females and homosexual males, while heterosexual females scored higher than homosexual

\footnotetext{
${ }^{1}$ Note, MANOVA is typically used because there are several non-orthogonal dependent variables in the study design (that is, thematically related dependents or domains). The relationships between SDO, empathy and the aggression variables are explored in the section 1 of this paper (Introduction).
} 
males. The difference in scores between heterosexual and homosexual males was particularly large in magnitude (Cohen's d of 0.99). These differences between groups were analogous for physical aggression, with the difference in scores between heterosexual and homosexual males again being particularly large in magnitude (Cohen's d of 1.00). In addition to these differences, heterosexual females displayed higher levels of anger than homosexual males, and homosexual males displayed higher levels of empathy than heterosexual males. There were no significant differences between the groups for guilt induction.

The $95 \%$ confidence intervals show no significant overlap of mean scores for SDO (heterosexual males $=44.73-53.87$; homosexual males $=30.26-37.17$; heterosexual females $=37.59-46.04)$, physical aggression (heterosexual males $=21.27-25.20$; homosexual males $=14.99-17.97$; heterosexual females $=17.89-21.78)$ or anger (heterosexual males $=15.12-18.12$; homosexual males $=14.26-16.94$; heterosexual females $=16.80-20.30$ ). Far more overlap was found for guilt induction (heterosexual males $=9.34-11.32 ;$ homosexual males $=9.51-11.62 ;$ heterosexual females $=10.94-$ 13.13) and empathy (heterosexual males $=22.71-26.12$; homosexual males $=26.22$ 29.41; heterosexual females $=25.55-27.45)$.

The baseline correlations between SDO and the other sub-scales, across sexual orientation, are shown below in Table IV:

[INSERT TABLE IV HERE] 
It is worth noting that empathy does not significantly correlate with SDO in any group, although the correlations are all negative.

\section{Discussion}

The present study has lent support to our hypotheses. Heterosexual males scored significantly higher on physical aggression than homosexual males and heterosexual females. Furthermore, heterosexual males have reported higher levels of social dominance orientation than homosexual males and heterosexual females.

As with Sergeant et al. (2006), homosexual males were found to have higher levels of empathy than heterosexual males, but empathy, although negatively correlated with SDO, was not significantly so, unlike Pratto et al. (1994). It is also interesting that no differences were found between the two heterosexual populations on any of the indirect aggression sub-scales. The mean scores on all of the subscales for heterosexual and homosexual males were comparable to those found in Sergeant et al. (2006), so we have no reason to suspect an unusual sample, although no females were measured by Sergeant et al. (2006) so a comparison cannot be made in this case.

Given this difference in SDO across sexual orientation we can tentatively continue to run the conditional argument begun in the introduction. If male homosexuality is a consequence of atypically low prenatal testosterone exposure, then one possible organizational outcome of this testosterone environment is the dispositional setting of SDO. The fact that heterosexual females scored higher on SDO than the homosexual 
male population indicates that there are other possible moderating factors to be taken into account that might include social factors, which were implicated, along with biological causes, by Sidanius et al. (1994). For example, it is possible that homosexual males, on average, suffer more social exclusion and prejudice, which might in turn alter their views on social dominance. It is not initially clear which way to make the prediction. Social exclusion could either lead to stringent in-group favouritism, as a form of protectionism, or to committed egalitarianism in order to tackle perceived injustice. However, LGBT societies, from which we have drawn our sample, are clearly organisations that are founded on a strong group identity. It is possible that such societies act either to encourage and consolidate fierce in-group views, or, to seek egalitarian interactions with the rest of society. The relationship between the kinds of legitimizing stories LGBT groups tell themselves and SDO would be of interest. Indeed, Levin, Sidanius, Rabinowitz and Federico (1998) have supported what they call the ideological asymmetry hypothesis which argues that "hierarchy-enhancing legitimizing ideologies should be positively associated with ingroup attachment among high-status groups" (p. 373), whereas in low-status groups this relationship should be reduced relative to the high-status groups. SDO, within high-status groups, would be expected to be positively related to such in-group favouritism (Levin, Federico, Sidanius and Rabinowitz, 2000). Given this, it is possible that the low SDO for our homosexual grouping is indicative of hierarchy attenuating values within the relevant LGBTs. One obvious way to test to this would be to sample individuals who are not members of such societies.

At the same time as investigating subtle social factors, further work needs to be done in order to more firmly establish the putative link between SDO and organizational 
hormones. One obvious line of future enquiry would be the use of proxy markers such as second-to-fourth digit ratio which might provide a more sensitive individual difference measure, bearing in mind issues of ethnicity.

\section{Conclusion}

There is good reason to suspect that directly aggressive behaviour differs across sexual orientations as does social dominance orientation. More work is required to thoroughly understand the aetiology of these effects as well as the strategic value of the behaviours, but for now we have reason to further investigate the organizational hormone hypothesis put forward in this paper.

\section{Acknowledgements}

The authors should like to thank the Brain, Behaviour and Cognition Research Group and Barbara Johnson, at the University of East London, as well as two anonymous reviewers for their useful comments on earlier drafts of this paper. 


\section{References:}

Archer, J. (2006). Testosterone and human aggression: an evaluation of the challenge hypothesis. Neuroscience and Biobehavioral Reviews, 30, 319-345.

Axelrod, R. \& Hammond, R.A. (2003.) The evolution of ethnocentric behaviour. Midwest Political Science Convention, 3 - 6 April 2003, Chicago, IL.

Bailey, A.A., \& Hurd, P.L. (2005). Finger length ratio (2D:4D) correlates with aggression in men but not in women. Biological Psychology, 68, 215-222.

Baron-Cohen, S. (2002). The extreme male brain theory of autism. Trends in Cognitive Science, 6, 248-254.

Baron-Cohen, S., Richler, J., Bisarya, Gurunathan, N., \& Wheelwright, S. (2003). The systemizing quotient: an investigation of adults with Asperger syndrome or highfunctioning autism, and normal sex differences. Philosophical Transactions of the Royal Society of London: Biological Sciences, 358, 361-374.

Baron-Cohen, S., \& Wheelwright, S. (2004). The empathy quotient: an investigation of adults with Aspergers's syndrome or high functioning autism, and normal sex differences. Journal of Autism and Developmental Disorders, 34, 163-175.

Berenbaum, S.A. (1999). Effects of early androgens on sex-typed activities and interests in adolescents with congenital adrenal hyperplasia. Hormones and Behavior, 35, 102-110. 
Berenbaum, S.A., \& Resnick, S.M. (1997). Early androgen effects on aggression in children and adults with congenital adrenal hyperplasia. Psychoneuroendocrinology, $22,505-515$.

Berenbaum, S.A., Duck, S.C., \& Bryk, K. (2000). Behavioral effects of postnatal versus prenatal androgen excess in children with 21-hydroxylase-deficient congenital adrenal hyperplasia. The Journal of Clinical Endocrinology and Metabolism, 85, 727733.

Blanchard, R. McConkey, J.G., Roper, V., \& Steiner, B. (1983). Measuring physical aggressiveness in heterosexual, homosexual and transsexual males. Archives of Sexual Behavior, 12, 77-84.

Buss, A.H., \& Perry, M. (1992). The aggression questionnaire. Personality and Individual Differences, 63, 452-459.

Campbell, A. (1995). A few good men: evolutionary psychology and female adolescent aggression. Ethology and Sociobiology, 16, 99-123.

Cohen, J. (1988). Statistical power analysis for the behavioral sciences: $2^{\text {nd }}$ Edition. New York: Academic Press.

Cohen-Bendahan, C.C.C., Buitelaar, J.K., van Goozen, S.H.M., Orlebeke, J.F., \& Cohen-Kettenis, P.T. (2005). Is there an effect of prenatal testosterone on prenatal 
aggression and other behavioural traits? a study comparing same-sex and opposite-sex twin girls. Hormones and Behavior, 47, 230-237.

Daly, M., \& Wilson, M. (1988). Homicide. New York: Alan de Gruyter.

Field, A. (2003). Discovering statistics using SPSS for Windows. London: Sage.

Forrest, S., Eatough, V., \& Shevlin, M. (2005). Measuring adult indirect aggression: the development and psychometric assessment of indirect aggression scales. Aggressive Behavior, 31, 84-97.

Gladue, B.A., \& Bailey, J.M. (1995). Aggressiveness, competitiveness and human sexual orientation. Psychoneuroendocrinology, 20, 475-485.

Harris, M.B. (1996). Personal aggressiveness: gender and aggression. Part 2. Sex Roles, 35, 27-42.

Joinson, A.N. (1999). Social desirability, anonymity and Internet-based questionnaires. Behavior Research Methods, Instruments, and Computers, 31, 433438.

Kinsey, A., Pomeroy, W., \& Martin, C. (1948). Sexual behavior in the human male. Philadelphia, PA: Saunders. 
Lawrence, E.J., Shaw, P., Baker, D., Baron-Cohen, S., \& David, A.S. (2004).

Measuring empathy: reliability and validity of the empathy quotient. Psychological Medicine, 34, 911-919.

Levin, S., Federico, C.M., Sidanius, J., \& Rabinowitz, J.L. (2002.) Social Dominance Orientation and Intergroup Bias: The Legitimation of Favoritism for High-Status Groups. Personality and Social Psychology Bulletin, 28, 144-157.

Levin, S., Sidanius, J., Rabinowitz, J.L., \& Federico, C. (1998.) Ethnic Identity. Legitimizing Ideologies, and Social Status: A Matter of Ideological Asymmetry. Political Psychology, 19 (2), 373-404.

Lippa, R.A. (2003.) Are 2D:4D Finger-Length Ratios Related to Sexual Orientation? Yes for Men, No for Women. Journal of Personality and Social Psychology, 85 (1), $179-188$.

Manning, J.T. (2002). Digit ratio: a pointer to fertility, behavior and health. New Jersey: Rutgers University Press.

Mazur, A., \& Booth, A. (1998.) Testosterone and dominance in men. Behavioral and Brain Sciences, 21, 353-397.

McFadden, D., Loehlin, J.C., Breedlove, S.M., Lippa, R.A., Manning, J.T., \& Rahman, Q. (2005.) A Reanalysis of Five Studies on Sexual Orientation and the 
Relative Length of the $2^{\text {nd }}$ and $4^{\text {th }}$ Fingers (the 2D:4D Ratio). Archives of Sexual Behaviour, 34 (3), 341-356.

Mesquida, C.G., \& Weiner, N.I. (1996). Human collective aggression: a behavioral ecological perspective. Ethology and Sociobiology, 17, 247-262.

Millet, K., \& Dewitte, S. (2006.) Second to fourth digit ratio and cooperative behaviour. Biological Psychology, 71, 111-115.

Neave, N., Laing, S., Fink, B., \& Manning, J.T. (2003). Second to fourth digit ratio, testosterone and perceived male dominance. Proceedings of the Royal Society of London: B, 270, 2167-2172.

Pratto, F., \& Hegarty, P. (2000). The political psychology of reproductive strategies. Psychological Science, 11, 57-62.

Pratto, F., Sidanius, J., Stallworth, L.M., \& Malle, B.F. (1994). Social dominance orientation: a personality variable predicting social and political attitudes. Journal of Personality and Social Psychology, 67, 741-763.

Rahman, Q., \& Wilson, G.D. (2003.) Born gay? The psychobiology of human sexual orientation. Personality and Individual Differences, 34, 1337-1382.

Sergeant, M.J.T., Dickins, T.E., Davies, M.N.O., \& Griffiths, M.D. (2006). Aggression, empathy and sexual orientation in males. Personality and Individual Differences, 40, 475-486. 
Sidanius, J., Pratto, F., \& Bobo, L. (1994). Social dominance orientation and the political psychology of gender: a case of invariance? Journal of Personality and Social Psychology, 67, 998-1011.

Sidanius, J., Levin, S., Liu, J., \& Pratto, F. (2000). Social dominance orientation, antiegalitarianism and the political psychology of gender: an extension and cross-cultural replication. European Journal of Social Psychology, 30, 41-67.

Sidanius, J., Pratto, F., van Laar, C., \& Levin, S. (2004). Social dominance theory: its agenda and method. Political Psychology, 25, 845-880.

Tooby, J. \& Cosmides, L. (1988.) The Evolution of War and Its Cognitive Foundations. Institute for Evolutionary Studies Technical Report 88-1.

Trivers, R. (1972). Parental investment and sexual selection. In B. Campbell (Ed.), Sexual selection and the descent of man (pp 136-179). Chicago: Aldine.

Van Vugt, M., De Cremer, D., \& Janssen, D.J. (2007.) Gender Differences in Cooperation and Competition: The Male-Warrior Hypothesis. Psychological Science, $18,19-23$

Wrangham, R.W. (1999.) Evolution of coalitionary killing. Yearbook of Physical Anthropology, 42, 1-30. 
Table I: Mean scores for SDO, direct aggression, indirect aggression and empathy

\begin{tabular}{|c|c|c|c|}
\hline Variable & Heterosexual Males & Heterosexual Females & Homosexual Males \\
\hline SDO & 49.30 (SD 17.68) & $41.82(\mathrm{SD} 16.34)$ & 33.72 (SD 13.39) \\
\hline Physical Aggression & $23.23(\mathrm{SD} 7.60)$ & $19.83(\mathrm{SD} 7.53)$ & $16.48(\mathrm{SD} 5.74)$ \\
\hline Verbal Aggression & $15.33(\mathrm{SD} 4.01)$ & $15.70(\mathrm{SD} 4.37)$ & $15.88(\mathrm{SD} 4.06)$ \\
\hline Anger & $16.62(\mathrm{SD} 5.80)$ & $18.55(\mathrm{SD} 6.76)$ & $15.60(\mathrm{SD} 5.20)$ \\
\hline Hostility & $22.05(\mathrm{SD} 6.73)$ & $23.07(\mathrm{SD} 7.61)$ & $22.22(\mathrm{SD} 7.02)$ \\
\hline Social Exclusion & $15.82(\mathrm{SD} 6.41)$ & $14.78(\mathrm{SD} 4.84)$ & $14.62(\mathrm{SD} 4.51)$ \\
\hline Malicious Humour & $16.58(\mathrm{SD} 6.89)$ & $15.12(\mathrm{SD} 5.22)$ & 15.48 (SD 5.07) \\
\hline Guilt Induction & $10.33(\mathrm{SD} 3.84)$ & $12.03(\mathrm{SD} 4.23)$ & $10.57(\mathrm{SD} 4.08)$ \\
\hline Empathy & $39.12($ SD 10.75) & 43.49 (SD 10.10) & $44.51(\mathrm{SD} 9.90)$ \\
\hline
\end{tabular}


Table II: Results of univariate analyses for aggression sub-traits and empathy

\begin{tabular}{lll} 
Variable & $\mathrm{F}_{(2,177)}$ & Effect size $(\eta 2)$ \\
\hline SDO & $14.41^{* *}$ & 0.14 \\
Physical Aggression & $13.90^{* *}$ & 0.14 \\
Verbal Aggression & 0.27 & 0.00 \\
Anger & $3.80^{*}$ & 0.04 \\
Hostility & 0.35 & 0.00 \\
Social Exclusion & 0.90 & 0.01 \\
Malicious Humour & 1.04 & 0.01 \\
Guilt Induction & $3.10^{*}$ & 0.03 \\
Empathy & $4.67 * *$ & 0.05 \\
* Significant at the 0.05 level & \\
** Significant at the 0.01 level &
\end{tabular}


Table III: Results of posthoc comparisons between sexual orientation groups

\begin{tabular}{llll}
\hline \hline Variable & Comparison & $\begin{array}{l}\text { Mean difference } \\
\text { in scores }\end{array}$ & $\begin{array}{l}\text { Effect size } \\
\text { (Cohen's d) }\end{array}$ \\
\hline SDO & HTM vs. HTF & $7.48^{*}$ & 0.44 \\
& HTM vs. HSM & $15.58^{* *}$ & 0.99 \\
& HTF vs. HSM & $8.10^{*}$ & 0.54 \\
Physical Aggression & HTM vs. HTF & $3.40^{*}$ & 0.45 \\
& HTM vs. HSM & $6.75^{* *}$ & 1.00 \\
Anger & HTF vs. HSM & $3.35^{*}$ & 0.50 \\
& HTM vs. HTF & -1.93 & -0.31 \\
& HTM vs. HSM & 1.02 & 0.19 \\
Guilt Induction & HTF vs. HSM & $2.95^{*}$ & 0.49 \\
& HTM vs. HTF & -1.70 & -0.42 \\
& HTM vs. HSM & -0.24 & -0.06 \\
Empathy & HTF vs. HSM & 1.46 & 0.35 \\
& HTM vs. HTF & -4.37 & -0.42 \\
& HTM vs. HSM & $-5.39^{* *}$ & -0.52 \\
& HTF vs. HSM & -1.02 & -0.10 \\
\hline
\end{tabular}

HTM = Heterosexual males; HTF $=$ Heterosexual females; HSM = Homosexual males

* Significant at the 0.05 level.

** Significant at the 0.01 level. 
Table IV: Pearson correlations of SDO with all of the scales across groups

\begin{tabular}{llll}
\hline \hline Variable & Heterosexual Males & Heterosexual Females & Homosexual Males \\
\hline Physical Aggression & $0.39^{* *}$ & $0.30^{* *}$ & $0.26^{*}$ \\
Verbal Aggression & $0.39^{* *}$ & $0.23^{*}$ & 0.17 \\
Anger & $0.39^{* *}$ & $0.26^{*}$ & -0.04 \\
Hostility & $0.38^{* *}$ & $0.26^{*}$ & 0.04 \\
Social Exclusion & $0.44^{* *}$ & 0.03 & $0.30^{* *}$ \\
Malicious Humour & $0.35^{* *}$ & 0.06 & $0.24^{*}$ \\
Guilt Induction & $0.48^{* *}$ & 0.13 & 0.21 \\
Empathy & -0.05 & -0.17 & -0.21 \\
\hline
\end{tabular}

* Significant at the 0.05 level.

** Significant at the 0.01 level. 